\title{
Ulrich L. Lehner, Enlightened Monks: The German Benedictines 1740-1803
}

Oxford, Oxford University Press, 2011, 266 p.

Daniel-Odon Hurel

\section{(2) OpenEdition}

\section{Journals}

Édition électronique

URL : http://journals.openedition.org/assr/24644

DOI : $10.4000 /$ assr. 24644

ISSN : $1777-5825$

Éditeur

Éditions de l'EHESS

Édition imprimée

Date de publication : 30 décembre 2012

Pagination : 226

ISSN : 0335-5985

Référence électronique

Daniel-Odon Hurel, «Ulrich L. Lehner, Enlightened Monks: The German Benedictines 1740-1803 », Archives de sciences sociales des religions [En ligne], 160 | octobre-décembre 2012, mis en ligne le 18 mars 2013, consulté le 21 septembre 2020. URL : http://journals.openedition.org/assr/24644 ; DOI : https://doi.org/10.4000/assr.24644

Ce document a été généré automatiquement le 21 septembre 2020.

(c) Archives de sciences sociales des religions 


\section{Ulrich L. Lehner, Enlightened Monks: The German Benedictines}

\section{0-1803}

Oxford, Oxford University Press, 2011, 266 p.

Daniel-Odon Hurel

\section{RÉFÉRENCE}

Ulrich L. Lehner, Enlightened Monks: The German Benedictines 1740-1803, Oxford, Oxford University Press, 2011, 266 p. 
1 Comprendre les interactions entre les moines-individus et leur institution, les relations entre liberté et obéissance, les liens entre les notions de "progrès » et de « tradition » chez les bénédictins, voici en quelque sorte le but de ce livre consacré au monde monastique bénédictin dans l'espace germanique au temps des Lumières. L'auteur envisage son propos dans une forme de confrontation méthodologique et historique permanente entre horizon ecclésiastique et horizon social. Il est aussi une étude qui analyse les connexions et les interactions entre la culture intellectuelle et la culture matérielle. En effet, l'auteur cherche à comprendre pourquoi les bénédictins ont produit plus d'hommes des lumières dans le catholicisme que tout autre ordre

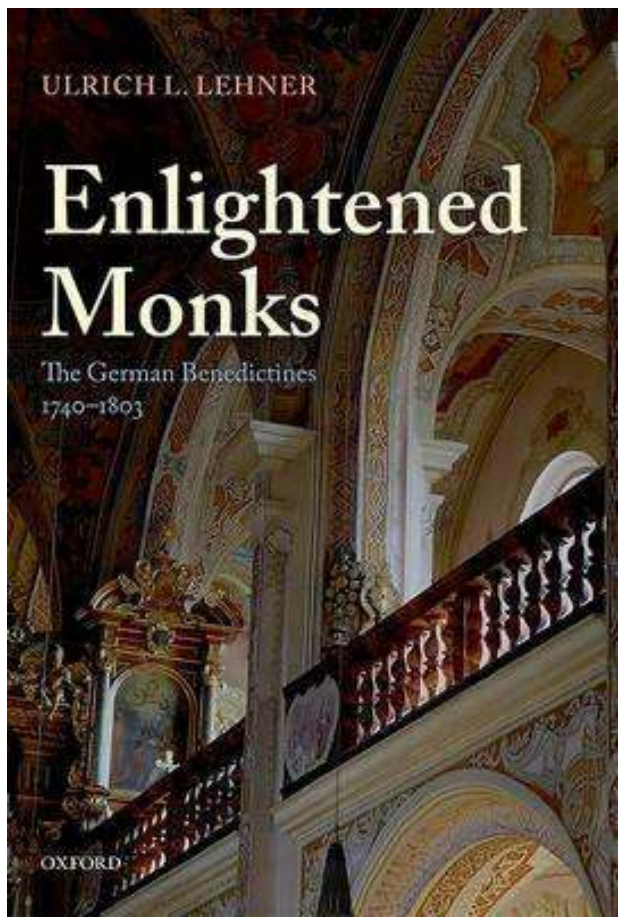
religieux. Il donne plusieurs pistes dont certaines sont propres au contexte germanique et d'autres plus larges : la décentralisation bénédictine (à la différence du modèle structurel mauriste) qui conduit chaque supérieur à ouvrir plus ou moins sa communauté aux Lumières ; la communication entre moines qui facilite les échanges et le transfert de connaissances; les échanges entre étudiants de différentes abbayes qui se multiplient; les échanges de livres et de nouvelles littéraires, particulièrement nombreux entre bibliothécaires et érudits des différents monastères, bénédictins ou non d'ailleurs; le modèle centralisé mauriste qui rejoint le modèle académique et les bénédictins allemands a donné à leur recherche une organisation et une structure claire; impact réel de cette communication sur l'implication des bénédictins dans les problèmes contemporains, tant en théologie qu'en philosophie, en science et dans le domaine de la politique ecclésiastique; enfin, constat d'une bonne réception des nouveautés et de leur appropriation au sein des communautés.

2 Parallèlement, l'auteur fait aussi une large place aux voix bénédictines de l'antiLumières. Après un chapitre consacré à la question historiographique tant sur le traitement de la question que sur l'écriture de l'histoire et sur les principaux acteurs bénédictins allemands eux-mêmes au XVIII ${ }^{\mathrm{e}}$ siècle (Hergott, Gerbert...) en lien direct ou indirect avec les mauristes, l'auteur aborde l'ensemble des éléments constitutifs de la vie monastique qui, dans leur évolution, sont aussi " acteurs » de ce monachisme des Lumières. Un nouveau mode de vie se dessine lié en particulier à la sociologie du recrutement et aux pratiques sociales (rapport à l'argent, usages du café, thé ou tabac, sociabilité mondaine, cabinets privés, jeux de cartes, voyages...) pour lesquelles l'auteur s'appuie sur quelques exemples. En lien avec cette évolution, il s'agit aussi de s'interroger sur l'évolution du rapport à la liberté individuelle dans le monachisme. En Allemagne comme en France d'ailleurs, s'affirment la liberté de correspondre, un rapport différent à l'obéissance, une forme de privatisation d'une part de la vie monastique, une connaissance plus précise des droits du moine et une remise en cause 
de l'exercice de l'autorité. Dans cette direction, l'auteur s'interroge dans un chapitre sur l'évolution de la question des prisons monastiques en lien avec les Lumières, s'appuyant en premier lieu sur le texte de Mabillon et sur certains exemples biographiques qui lui permettent aussi d'étudier la question des moines fugitifs ou sortis du cloître qui augmenteraient après 1740. L'intégration des bénédictins allemands au monde des Lumières passe aussi par une parfaite maitrise des outils de communications qui, en dehors de la traditionnelle correspondance, comprennent les sociétés savantes et les journaux. C'est ainsi que les bénédictins rejoignent ces nouveaux réseaux et participent ainsi à la transformation du savoir. Dans ce sens, l'auteur cite les académies fondées par des bénédictins, l'orientation vers la physique des travaux d'autres religieux, la fondation de journaux ou, plus encore, la maitrise des nouvelles théories juridiques par certains religieux, voire l'engagement actif des bénédictins allemands dans le dialogue avec les courants philosophiques nouveaux. Sans aucun doute, ce livre est important dans la mesure où, à partir du cas des bénédictins " allemands ", il renouvelle une approche, mais rejoint aussi les travaux en cours sur l'histoire du monachisme des Lumières en Europe. 